\title{
Short communication: Differential loss of bovine mammary epithelial barrier integrity in response to lipopolysaccharide and lipoteichoic acid
}

\author{
Olga Wellnitz, ${ }^{* 1}$ Christina Zbinden, ${ }^{*} \dagger$ Xiao Huang, $\ddagger$ and Rupert M. Bruckmaier ${ }^{*}$ \\ *Veterinary Physiology, Vetsuisse Faculty University of Bern, \\ †Graduate School for Cellular and Biomedical Sciences, and \\ łInstitute of Biochemistry and Molecular Medicine, University of Bern, CH-3012 Bern, Switzerland
}

\section{ABSTRACT}

In the mammary gland, the blood-milk barrier prevents an uncontrolled intermixture of blood and milk constituents and hence maintains the osmotic gradient to draw water into the mammary secretion. During mastitis, the permeability of the blood-milk barrier is increased, which is reflected by the transfer of blood constituents into milk and vice versa. In this study, we aimed to investigate changes in the barrier function of mammary epithelial cells in vitro as induced by cell wall components of different pathogens. Primary bovine mammary epithelial cells from 3 different cows were grown separately on Transwell (Corning Inc., Corning, NY) inserts. The formation of tight junctions between adjacent epithelial cells was shown by transmission electron microscopy and by immunofluorescence staining of the tight junction protein zona occludens-1. The integrity of the epithelial barrier was assayed by means of transepithelial electrical resistance, as well as by diffusion of the fluorophore Lucifer yellow across the cell layer. The release of lactate dehydrogenase (LDH) was used as an indicator for cytotoxic effects. In response to a 24-h challenge with bacterial endotoxin, barrier integrity was reduced after 3 or $7 \mathrm{~h}$, respectively, in response to $0.5 \mathrm{mg} / \mathrm{mL}$ lipopolysaccharide (LPS) from Escherichia coli or $20 \mathrm{mg} / \mathrm{mL}$ lipoteichoic acid (LTA) from Staphylococcus aureus. No paracellular leakage was observed in response to $0.2 \mathrm{mg} / \mathrm{mL}$ LPS or $2 \mathrm{mg} /$ mL LTA. Although LPS and LTA affected barrier permeability, most likely by opening the tight junctions, only LPS caused cell damage, reflected by increased $\mathrm{LDH}$ concentrations in cell culture medium. These results prove a pathogen-specific loss of blood-milk barrier integrity during mastitis, which is characterized

Received January 21, 2016.

Accepted February 20, 2016.

${ }^{1}$ Corresponding author: olga.wellnitz@vetsuisse.unibe.ch by tight junction opening by both LPS and LTA and by additional epithelial cell destruction through LPS.

Key words: mammary, mastitis, blood-milk barrier, tight junction

\section{Short Communication}

In the bovine mammary gland, the milk-producing mammary epithelial cells lining the alveoli are involved in the formation of the blood-milk barrier that prevents uncontrolled intermixture of blood and milk (Nguyen and Neville, 1998). Intramammary infections, besides specific physiological stages of the mammary gland like lactogenesis and involution, lead to reduced blood-milk barrier integrity (Linzell and Peaker, 1972; Nguyen and Neville, 1998). This reduction of blood-milk barrier integrity increases the appearance of blood-derived substances in the milk (Stelwagen, 2001; Wheeler et al., 2007; Lehmann et al., 2013; Stelwagen and Singh, 2014). Consequently, the composition of mastitic milk is considerably changed: as well as increased SCC, other blood components such as serum albumin or $\mathrm{IgG}_{2}$ antibodies can be detected (Burton and Erskine, 2003; Wellnitz et al., 2013). These changes can reduce the quality of milk enormously but also support the innate immune system, as the increased appearance of antibodies in milk can opsonize invaded pathogens for neutrophil phagocytosis (Burton and Erskine, 2003).

Alteration of the blood-milk barrier is caused, at least in part, by an opening of the tight junctions (Burton and Erskine, 2003). Tight junctions seal adjacent mammary epithelial cells, preventing paracellular transport of ions and small molecules. Furthermore, they establish cell polarity by dividing the plasma membrane into apical and basolateral domains (Schneeberger and Lynch, 1992; Stevenson and Keon, 1998).

The loss of blood-milk barrier integrity during mastitis was observed to be pathogen-specific: experimentally induced mastitis by Escherichia coli-derived LPS resulted in a more pronounced transfer of blood components, including $\operatorname{IgG}_{2}$, into milk than mastitis induced 
by lipoteichoic acid (LTA) from Staphylococcus aureus, even though the increase of SCC was similar (Wellnitz et al., 2013). A differential transfer of blood components induced by different pathogens could influence the course and the healing process of mastitis. Therefore, the objective of the present study was to investigate the pathogen-specific mechanisms of the impairment of the blood-milk barrier during mastitis. In an in vitro model of bovine mammary epithelial cells, barrier integrity and tight junction formation was established. The effects of the bacterial cell wall components LPS and LTA from the mastitis pathogens Escherichia coli and Staphylococcus aureus, respectively, on epithelial barrier integrity and cytotoxicity were investigated.

Primary bovine mammary epithelial cells (pbMEC) of 3 lactating Holstein dairy cows with clinically healthy udders (SCC $<10^{5}$ cells $/ \mathrm{mL}$ ) were isolated directly after slaughter and cryopreserved in the first passage as previously described (Wellnitz and Kerr, 2004). Cells of all 3 cows were seeded separately at concentrations of $10^{5}$ cells $/ \mathrm{cm}^{2}$ onto $0.4-\mu \mathrm{m}$ Transwell polyester membrane inserts in 12-well cell culture plates (Corning Inc., Corning, NY). Cells were grown in 1.5 and $0.5 \mathrm{~mL}$ of growth medium on the basolateral and apical sides, respectively, for 4 to $5 \mathrm{~d}$ in the presence of $5 \% \mathrm{CO}_{2}$ at $37^{\circ} \mathrm{C}$. Medium was changed every $48 \mathrm{~h}$.

To visualize the cell contacts by electron microscopy, pbMEC grown on Transwell inserts were washed with PBS and fixed in $2.5 \%$ glutaraldehyde in $0.15 M$ HEPES buffer (707 mOsm, $\mathrm{pH} 7.4$ ) at $4^{\circ} \mathrm{C}$ for several days. Cells were then washed with $0.15 M$ HEPES buffer and fixed for $1 \mathrm{~h}$ in $1 \% \mathrm{OsO}_{4}$ in $0.1 \mathrm{M}$ sodium cacodylate buffer (total osmolarity: $369 \mathrm{mOsm}, \mathrm{pH}$ 7.4). After washing with $0.05 \mathrm{M}$ maleate- $\mathrm{NaOH}$ buffer ( $\mathrm{pH} 5.0$ ), the membranes were dehydrated in 70,80 , and $96 \%$ ethanol each for $15 \mathrm{~min}$ at room temperature. Subsequently, cells were immersed in $100 \%$ ethanol 3 times for 15 min, incubated in ethanol-epon (1:1) overnight at room temperature, embedded in epon, and left to polymerize at $60^{\circ} \mathrm{C}$ for $4 \mathrm{~d}$. Ultrathin sections $(70 \mathrm{~nm})$ were cut on a Reichert-Jung Ultracut E microtome (Leica Microsystems, Vienna, Austria), mounted on polyvinyl formal (formvar)-coated 2- $\times 1$-mm single-slot copper grids, and double-stained with $1 \%$ uranyl acetate and $3 \%$ lead citrate. Transmission electron microscopy (EM 400, Philips, Eindhoven, the Netherlands) indicated that the pbMEC displayed specific structural features of epithelial tissues (Figure 1): a continuous layer of cells was formed with apico-basal polarity. The basal membrane was attached to the Transwell membrane. Microvilli were formed on the luminal cell surface, and intercellular junctions were visible between neighboring cells. As described previously in mammary cells (Pick- ett et al., 1975), these connections include desmosomes and tight junctions.

To confirm the existence of tight junctions between adjacent cells, pbMEC of all 3 cows were separately seeded on collagen-coated coverslips and cultured until confluency. Immunofluorescent labeling of the tight junction protein zona occludens-1 (ZO-1) in pbMEC grown on coverslips was performed as described previously (Hernandez et al., 2011) using a monoclonal mouse anti-human, anti-dog ZO-1 antibody (Molecular Probes/Thermo Fisher Scientific, Waltham, MA). Visualization using a fluorescence microscope (BX41, Olympus, Center Valley, PA) showed that ZO-1 was expressed at the intercellular contacts of pbMEC (Figure 2).

After confirmation of cell connections, the barrier function of the pbMEC on Transwells was evaluated by 2 complementary assays: transepithelial electrical resistance (TEER) and diffusion of the fluorescent dye Lucifer yellow (LY) across confluent layers of pbMEC. For measurement of TEER, an epithelial volt-ohmmeter (World Precision Instruments, Sarasota, FL) was used as described by Ma et al. (1999). The TEER value is inversely proportional to the permeability, and it represents a marker for intercellular tight junction integrity (Berkes et al., 2003). The mean of 3 Transwell inserts with pbMEC successively measured 3 times resulted in a TEER value of $1,531 \pm 75 \Omega \mathrm{cm}^{2}$ and that of a Transwell insert without any cells was $135 \pm 7 \Omega \mathrm{cm}^{2}$, demonstrating that primary pbMEC from different cows cultured on Transwell inserts were able to form a cell layer with tight intercellular connections.

To determine dynamic changes in barrier integrity in response to different mastitis pathogens, we challenged cells with LPS and LTA. Cells of 3 cows were cultured separately on Transwell inserts and grown for 4 to $5 \mathrm{~d}$ until they formed tight cell layers, confirmed by a TEER $>1,500 \Omega \mathrm{cm}^{2}$. Before endotoxin treatment, inserts were washed twice with Dulbecco's PBS (Sigma-Aldrich, Buchs, Switzerland), and the growth medium was replaced in both chambers. Then, 0.2 or $0.5 \mathrm{mg} / \mathrm{mL}$ LPS or 2 or $20 \mathrm{mg} / \mathrm{mL}$ LTA (SigmaAldrich) was added to the upper chamber. The permeability of the epithelial barrier was detected by paracellular diffusion of LY in the following manner: $0.5 \mathrm{~mL}$ of $50 \mu \mathrm{M} \mathrm{LY}$ (Lucifer yellow $\mathrm{CH}$ lithium salt; Biotium, Hayward, CA), suspended in phenol red-free Dulbecco's modified Eagle's medium supplemented with $2.5 \mathrm{~m} M$ L-glutamine (Sigma-Aldrich) and $5 \%$ fetal bovine serum (LY assay medium), was added to the apical compartment of Transwell inserts, and $1.5 \mathrm{~mL}$ of LY assay medium alone was added to the basolateral compartment. The paracellular diffusion of membrane- 


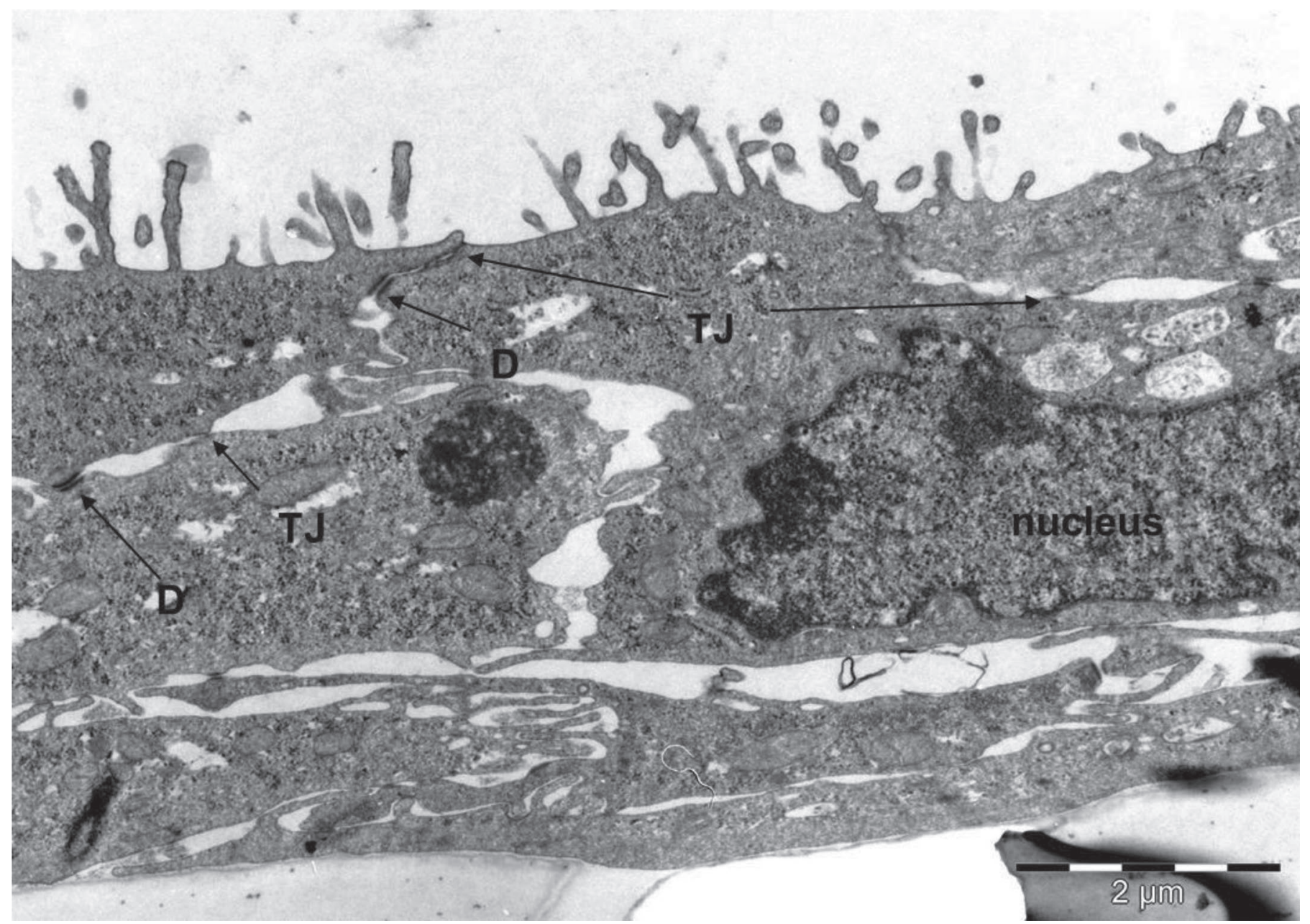

Figure 1. Transmission electron micrograph of representative Transwell-grown primary bovine mammary epithelial cells from one cow. Cells are attached to the membrane of the Transwell insert. Microvilli are formed at the luminal cell surface. Cells are connected by cell junctions: desmosomes (D) and tight junctions (TJ) are indicated by arrows.

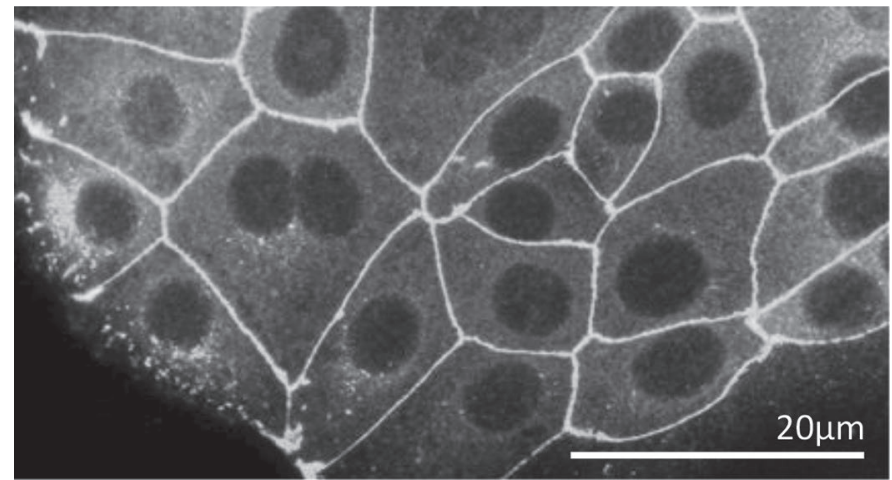

Figure 2. Representative immunofluorescence of the tight junction protein zona occludens-1 (ZO-1) in cultured primary bovine mammary epithelial cells from one cow stained for ZO-1. The formation of tight junctions is reflected by a continuous distribution of ZO-1 along the intercellular contacts. A magnified $(400 \times)$ immunofluorescent image is shown. Immunofluorescent staining of ZO-1 in LPS- or lipoteichoic acid (LTA)-treated cells was not performed. impermeant fluorophores, including LY, is often used to study the permeability of epithelia and endothelia in vitro (Young et al., 2006). The top-down diffusion of LY across pbMEC was monitored using a fluorescence plate reader (Synergy2, BioTek Instruments, Winooski, $\mathrm{VT}$ ) by measuring the fluorescence every hour for $24 \mathrm{~h}$ at $530 \mathrm{~nm}$ and $37^{\circ} \mathrm{C}$, which allowed for the recording of time-dependent changes in epithelial barrier permeability. At the end of the experiment, Transwell inserts were removed, and the fluorescence was measured in the basolateral chambers to confirm paracellular diffusion. Inserts with untreated cells and without cells served as negative control and blank, respectively.

Fluorescence in the upper compartment throughout the experiment is shown in Figure 3. All data are expressed as means \pm SEM from 3 Transwells (i.e., cells from 3 cows). Statistical analysis was performed using a 2-tailed paired $t$-test of SAS (release 9.4; SAS Insti- 
tute Inc., Cary, NC) and a confidence level $>95 \%(P<$ 0.05). The challenge of pbMEC with $20 \mathrm{mg} / \mathrm{mL}$ LTA resulted in a significant reduction of LY from $7 \mathrm{~h}$ until the end of the experiment after $24 \mathrm{~h}$ of incubation. In Transwells where cells were challenged with $0.5 \mathrm{mg} /$ $\mathrm{mL}$ LPS, the passage of LY was significantly increased from 3 to $24 \mathrm{~h}$ of challenge. Neither $2 \mathrm{mg} / \mathrm{mL}$ LTA nor $0.2 \mathrm{mg} / \mathrm{mL}$ LPS had a significant effect on pbMEC permeability. The paracellular transport of LY across untreated control cell layers was minimal. After $24 \mathrm{~h}$, the fluorescence values (relative fluorescence units, RFU) in the basolateral compartments were 1,066 \pm $186,180 \pm 18,1,057 \pm 81$, and $362 \pm 48 \mathrm{RFU}$ for 20 $\mathrm{mg} / \mathrm{mL} \mathrm{LTA}, 2 \mathrm{mg} / \mathrm{mL}$ LTA, $0.5 \mathrm{mg} / \mathrm{mL}$ LPS, and 0.2 $\mathrm{mg} / \mathrm{mL}$ LPS, respectively. The basolateral fluorescence for negative control cells reached $213 \pm 31$ RFU.

A recent in vivo study showed that LPS and LTA result in increased permeability of the blood-milk barrier to different extents (Wellnitz et al., 2013), with LPS inducing a more efficient transfer of blood components, including immunoglobulins, into the milk compared with LTA. In accordance with these findings, the present study demonstrated a dose-dependent impairment of barrier function of Transwell-grown pbMEC challenged with LPS or LTA.

In the in vivo study of Wellnitz et al. (2013), a concentration of LTA 100 times greater than that of LPS (i.e., $20 \mu \mathrm{g}$ of LTA vs. $0.2 \mu \mathrm{g}$ of LPS) was administered into one udder quarter to obtain an immune response accompanied by a similar increase of SCC. It was demonstrated previously in cell culture that much greater amounts of LTA are needed to elicit inflammatory responses compared with LPS, and this is comparable if transposed to bacterial cell equivalents (Fournier and Philpott, 2005). In the present study, concentrations of LTA 4 to 100 times higher were applied, with the objective of obtaining a leaky pbMEC layer. This was achieved by $0.5 \mathrm{mg} / \mathrm{mL}$ LPS or $20 \mathrm{mg} / \mathrm{mL}$ LTA.

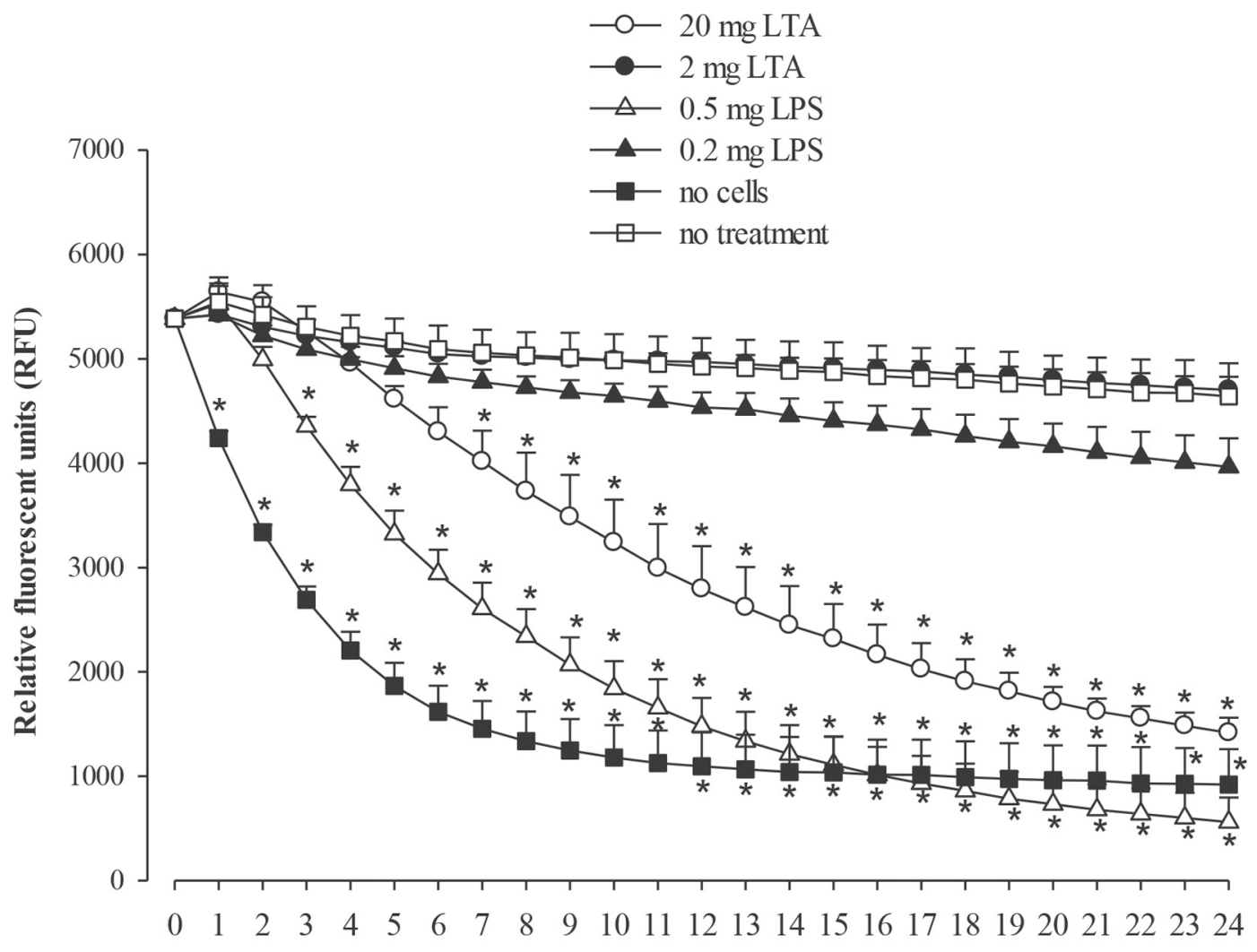

Time after challenge (h)

Figure 3. Diffusion of Lucifer yellow across filter-grown (in Transwells) primary bovine mammary epithelial cells challenged with LPS or lipoteichoic acid (LTA). The fluorescence in the upper compartment of the Transwell insert was monitored by a fluorescence plate reader. The mean \pm SEM of RFU in Transwells with cells from 3 cows for each time point are shown. Cells were challenged for $24 \mathrm{~h} \mathrm{with} 0.2 \mathrm{or} 0.5 \mathrm{mg} / \mathrm{mL}$ LPS or with 2 or $20 \mathrm{mg} / \mathrm{mL}$ LTA. Untreated cells and inserts without cells (blanks) served as controls. Asterisk indicates significant differences compared with control $(\square$; untreated cells) at the same time point $(P<0.05)$. 


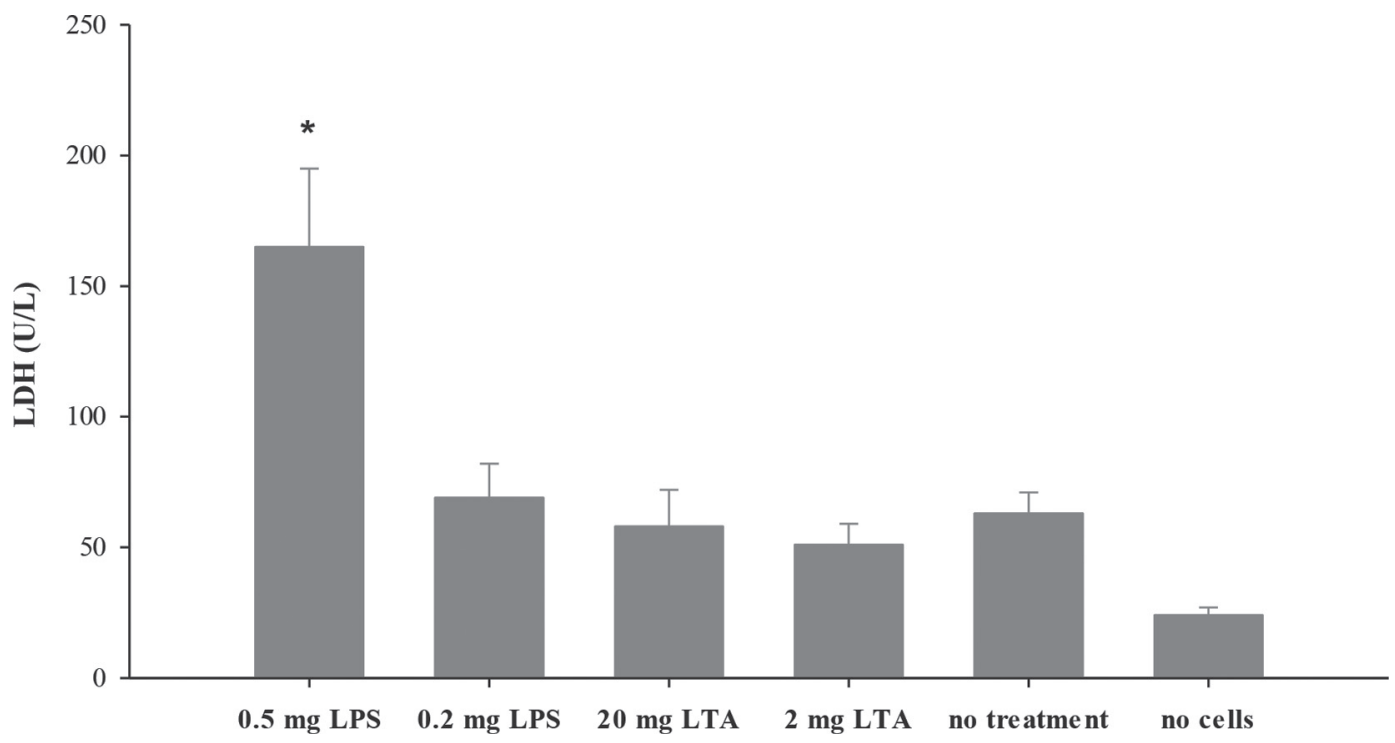

Figure 4. Lactate dehydrogenase (LDH) activity in cell culture supernatants from primary bovine mammary epithelial cells with and without challenge with LPS or lipoteichoic acid (LTA) after $24 \mathrm{~h}$. Data are presented as means \pm SEM from cells from each cow (n $=3$ ). Asterisk indicates significantly higher activity compared with negative controls $(P<0.05)$.

Although a lower concentration of LPS was used, it induced a faster and more pronounced permeability and therefore a faster passage of LY compared with LTA.

The effect of bacterial endotoxin on tight junction permeability has been reported repeatedly in various species and tissues (Chakravortty and Kumar, 1999; Guo et al., 2013; Kobayashi et al., 2013). However, it is assumed the alteration of the blood-milk barrier is also induced by epithelial cell damage (Wagner et al., 2009; Akers and Nickerson, 2011). In the present study, the release of lactate dehydrogenase (LDH) into the cell culture supernatant was used as an indicator of cytotoxicity of the LPS and LTA treatments. The enzyme $\mathrm{LDH}$, a common indicator for cell viability in vitro, is released from damaged cells (Glick, 1969). Cell culture supernatants were collected after a 24-h co-incubation with LPS or LTA. As a negative control, cells without LPS or LTA were used. The LDH activity was measured using a commercial kit (AxonLab AG, Baden, Switzerland) compatible with a Cobas Mira automated analyzer (Roche Diagnostics, Basel, Switzerland) according to the manufacturer's instructions. Interestingly, a cytotoxic effect (i.e., a considerably increased release of LDH into cell culture supernatant) was observed in pbMEC challenged with $0.5 \mathrm{mg} / \mathrm{mL}$ LPS but not cells challenged with $20 \mathrm{mg} / \mathrm{mL} \mathrm{LTA}$, even though this LTA treatment decreased the epithelial barrier integrity (Figures 3 and 4). Therefore, cell disruption clearly contributes, most likely combined with an alteration of the tight junctional complex, to the increased paracellular permeability induced by LPS. In contrast, the finding that $20 \mathrm{mg} / \mathrm{mL}$ LTA resulted in increased permeability without evident cell damage suggests that LTA affects monolayer permeability solely through the regulation of tight junctions.

\section{CONCLUSIONS}

In the current study, we showed that growth of pbMEC from different cows on Transwell inserts is a suitable model to investigate epithelial barrier function during an immune response to different mastitis pathogens. Bacterial endotoxins, such as LPS from the common mastitis pathogens $E$. coli and LTA from $S$. aureus, clearly affect barrier integrity. It is likely that disruption of the tight junctions between the mammary epithelial cells is involved. Interestingly, LPS causes an additional impairment of barrier function by cell disruption. This finding is of substantial importance in understanding pathogen-specific development of mastitis and in optimizing pathogen-specific therapy of mastitis.

\section{ACKNOWLEDGMENTS}

This study was supported by a grant of the Swiss National Foundation (Bern, Switzerland; grant no. 149460). Electron microscopy was performed at the Institute of Anatomy, University of Bern, Switzerland, with the help of Franziska Graber, which is greatly appreciated. 


\section{REFERENCES}

Akers, R. M., and S. C. Nickerson. 2011. Mastitis and its impact on structure and function in the ruminant mammary gland. J. Mammary Gland Biol. Neoplasia 16:275-289.

Berkes, J., V. K. Viswanathan, S. D. Savkovic, and G. Hecht. 2003. Intestinal epithelial responses to enteric pathogens: Effects on the tight junction barrier, ion transport, and inflammation. Gut $52: 439-451$.

Burton, J. L., and R. J. Erskine. 2003. Immunity and mastitis. Some new ideas for an old disease. Vet. Clin. North Am. Food Anim. Pract. 19:1-45.

Chakravortty, D., and K. S. Kumar. 1999. Modulation of barrier function of small intestinal epithelial cells by lamina propria fibroblasts in response to lipopolysaccharide: Possible role in TNFalpha in inducing barrier dysfunction. Microbiol. Immunol. 43:527-533.

Fournier, B., and D. J. Philpott. 2005. Recognition of Staphylococcus aureus by the innate immune system. Clin. Microbiol. Rev. 18:521-540.

Glick, J. H. Jr. 1969. Serum lactate dehydrogenase isoenzyme and total lactate dehydrogenase values in health and disease, and clinical evaluation of these tests by means of discriminant analysis. Am. J. Clin. Pathol. 52:320-328.

Guo, S., R. Al-Sadi, H. M. Said, and T. Y. Ma. 2013. Lipopolysaccharide causes an increase in intestinal tight junction permeability in vitro and in vivo by inducing enterocyte membrane expression and localization of TLR-4 and CD14. Am. J. Pathol. 182:375-387.

Hernandez, L. L., J. L. Collier, A. J. Vomachka, R. J. Collier, and N. D. Horseman. 2011. Suppression of lactation and acceleration of involution in the bovine mammary gland by a selective serotonin reuptake inhibitor. J. Endocrinol. 209:45-54.

Kobayashi, K., S. Oyama, A. Numata, M. M. Rahman, and H. Kumura. 2013. Lipopolysaccharide disrupts the milk-blood barrier by modulating claudins in mammary alveolar tight junctions. PLoS ONE 8:e62187.

Lehmann, M., O. Wellnitz, and R. M. Bruckmaier. 2013. Concomitant lipopolysaccharide-induced transfer of blood-derived components including immunoglobulins into milk. J. Dairy Sci. 96:889-896.

Linzell, J. L., and M. Peaker. 1972. Day-to-day variations in milk composition in the goat and cow as a guide to the detection of subclinical mastitis. Br. Vet. J. 128:284-295.
Ma, T. Y., D. Nguyen, V. Bui, H. Nguyen, and N. Hoa. 1999. Ethanol modulation of intestinal epithelial tight junction barrier. Am. J. Physiol. 276:G965-G974.

Nguyen, D. A., and M. C. Neville. 1998. Tight junction regulation in the mammary gland. J. Mammary Gland Biol. Neoplasia 3:233246.

Pickett, P. B., D. R. Pitelka, S. T. Hamamoto, and D. S. Misfeldt. 1975. Occluding junctions and cell behavior in primary cultures of normal and neoplastic mammary gland cells. J. Cell Biol. 66:316332 .

Schneeberger, E. E., and R. D. Lynch. 1992. Structure, function, and regulation of cellular tight junctions. Am. J. Physiol. 262:L647L661.

Stelwagen, K. 2001. Effect of milking frequency on mammary functioning and shape of the lactation curve. J. Dairy Sci. 84:E204-E211.

Stelwagen, K., and K. Singh. 2014. The role of tight junctions in mammary gland function. J. Mammary Gland Biol. Neoplasia 19:131138.

Stevenson, B. R., and B. H. Keon. 1998. The tight junction: Morphology to molecules. Annu. Rev. Cell Dev. Biol. 14:89-109.

Wagner, S. A., D. E. Jones, and M. D. Apley. 2009. Effect of endotoxic mastitis on epithelial cell numbers in the milk of dairy cows. Am. J. Vet. Res. 70:796-799.

Wellnitz, O., E. T. Arnold, M. Lehmann, and R. M. Bruckmaier. 2013 Short communication: differential immunoglobulin transfer during mastitis challenge by pathogen-specific components. J. Dairy Sci. 96:1681-1684.

Wellnitz, O., and D. E. Kerr. 2004. Cryopreserved bovine mammary cells to model epithelial response to infection. Vet. Immunol. Immunopathol. 101:191-202.

Wheeler, T. T., A. J. Hodgkinson, C. G. Prosser, and S. R. Davis 2007. Immune components of colostrum and milk-A historical perspective. J. Mammary Gland Biol. Neoplasia 12:237-247.

Young, A. M., K. L. Audus, J. Proudfoot, and M. Yazdanian. 2006. Tetrazole compounds: The effect of structure and $\mathrm{pH}$ on Caco-2 cell permeability. J. Pharm. Sci. 95:717-725. 